\title{
Aortic valvuloplasty of calcific aortic stenosis with monofoil and trefoil balloon catheters: practical considerations*
}

An evaluation of balloon design and valvular morphology relationship, derived from experimental and clinicopathological observations

\author{
S. Plante, M. van den Brand, L.C.P. van Veen ${ }^{1}$, C. Di Mario, C.E. Essed ${ }^{2}$, K.J. Beatt \& P.W. Serruys \\ Thoraxcenter (Catheterization Laboratory), ' Experimental Radiology and ${ }^{2}$ Pathology Department 1, \\ Erasmus University, Rotterdam, The Netherlands
}

Key words: aortic valvuloplasty, aortic stenosis, balloon catheters, computed axial tomography

\section{Summary}

In order to evaluate the relation between balloon design (monofoil, trefoil) and valvular configuration, experimental aortic valvuloplasty was performed in four post-mortem hearts with calcific aortic stenosis of various morphology. The degree of obstruction of the aortic orifice was assessed by computed axial tomography during inflation of monofoil 15 and $19 \mathrm{~mm}$ and trefoil $3 \times 12 \mathrm{~mm}$ balloon catheters. We also evaluated the hemodynamic repercussion of balloon inflation (fall in systolic aortic pressure) in four elderly patients with acquired aortic stenosis who underwent a percutaneous transluminal aortic balloon valvuloplasty, with stepwise increasing balloon sizes of $15 \mathrm{~mm}, 19 \mathrm{~mm}$ and $3 \times 12 \mathrm{~mm}$, as during our in vitro experiments, and who underwent aortic valve replacement later on. In these patients, we correlated the anatomy of the excised aortic valves with the retrospective analysis of aortic pressure curves recorded during previous valvuloplasty procedures.

Our experimental and clinicopathological observations showed that the degree of obstruction of the aortic orifice in post-mortem specimens and the tolerance to balloon inflation in live patients are dependent of the valvular configuration. Although trefoil balloons have the theoretical advantage to avoid complete obstruction of the aortic orifice during inflation, we observed that in presence of a tricuspid configuration, they could be potentially more occlusive than monofoil balloons since each of the 3 individual components of the trefoil balloon occupied the intercommissural spaces while inflated. However, they offered more residual free space when inflated in aortic valves with a bicuspid configuration (i.e. congenitally bicuspid valves or tricuspid valves with one fused commissure).

In our opinion, these observations are relevant, since degenerative disease of the aortic valve (i.e, tricuspid valve without commissural fusion) is now recognized as the most common etiology of aortic stenosis in the elderly.

Abbreviations: $\mathrm{AS}=$ aortic stenosis; $\mathrm{AVA}=$ aortic valve area; PTAV = percutaneous transluminal aortic balloon valvuloplasty

\footnotetext{
* A video supplement to this article has been published in Cardiac Imaging Video Journal volume 2, nr. 4, 1989 , see Reference 29.
} 


\section{Introduction}

Percutaneous transluminal aortic balloon valvuloplasty (PTAV) for acquired aortic stenosis (AS) has been introduced a few years ago as an alternative for valve replacement in patients with high surgical risk or for those who refused surgical intervention $[1,2]$. Procedure-related complications, limited hemodynamic improvement and the high recurrence rate reported until now [3-16] have decreased the initial enthusiasm for this relatively new technique.

Despite these current limitations, PTAV is currently regarded by many cardiologists as a palliative treatment in a subset of patients with prohibitive surgical risk. Some authors recently advocated PTAV as a 'bridge' procedure to improve left ventricular function before aortic valve replacement or non-cardiac surgery $[17,18]$.

However, other shortcomings of the procedure are 1) the largely unpredictable individual tolerance to balloon inflation (hypotension) and 2) the unpredictable immediate hemodynamic results in an individual patient. The incidence of non-responding or poorly responding patients (aortic valve area still $<0.7 \mathrm{~cm}^{2}$ at the end of the procedure) is ranging from $18.7 \%$ to $38.2 \%$ [12]. These facts suggest that some morphological aspects (bicuspid or tricuspid valve, fused or non-fused commissures) or other factors like the volume occupied by nodular calcifications and residual elasticity of some leaflets [19] can adversely influence the hemodynamic results of the procedure. Furthermore, it seems conceivable that balloon catheters of different shapes (monofoil, bifoil, trefoil) operate with distinct mechanisms of dilatation in the presence of a specific valvular morphology.

To circumvent hypotensive responses during balloon inflation, trefoil balloon catheters have been introduced recently. Attractive advantages of this device have been demonstrated in animal experiments [20] and it has been effective in allowing continuous blood flow during inflation in the setting of pulmonary valvuloplasty in adults [21], aortic valvuloplasty in children and young adults [22], and in mitral and aortic valvuloplasty in adults [23-24]. However, the degenerative, remodeling and calcifying process peculiar to acquired AS in elderly patients differs largely from the pathological changes observed in congenital and rheumatic valvular diseases; this may explain why some of these patients still present abrupt and severe falls in aortic pressure, even when PTAV is performed with trefoil balloon catheters. In order to achieve better hemodynamic results and to obtain technical refinements in the valvuloplasty material, we have to improve our knowledge of the operational mechanisms of dilatation. Intra-operative, postmortem and experimental studies on the mechanisms of aortic valvuloplasty have been reported until now, based mainly on visual inspection and low-energy $x$-ray techniques $[19,25-27]$. In order to obtain detailed quantitative information on the intravalvular calcium distribution before and after valvuloplasty and to further elucidate the operational mechanisms of dilatation, we have performed thin-slice computed tomographic scanning in post-mortem hearts with calcific AS before, during and after balloon valvuloplasty [28]. This technique avoided superimposition of structures and provided vastly superior density resolution compared to conventional $x$-ray techniques. In our study, fracture of nodular calcifications, commissural separation and central raphe splitting were the observed mechanisms of balloon valvuloplasty. However, calcium redistribution [27] could not be recognized as an operational mechanism, since no dilatation-related modification in density and volume of the calcific deposits was observed with computed tomographic scanning. Furthermore, computed axial tomography provided useful information concerning the relations between balloon size and shape and valvular configuration. To our knowledge, few reports have focused on this particular aspect of aortic balloon valvuloplasty.

In this article, we describe our experimental and clinicopathological observations related to aortic valvuloplasty performed with single circular (monofoil) and trefoil balloon catheters in human hearts with acquired AS. We will present a review of our previous experimental findings and we will correlate these results with our recent clinicopathological observations, based on retrospective analy- 
sis of valvuloplasty procedures performed in some patients who underwent subsequently a valve replacement and from whom excised aortic valves were available for anatomopathological evaluation. For more detailed information concerning our in vitro experiments, the reader is referred to our previous publication [28]. Our experimental findings have been published in video format, see reference 29 .

\section{Experimental valvuloplasty}

\section{Material and methods}

Four hearts with calcific, stenotic aortic valves and intact aortic rings were selected from our collection of autopsy specimens (Pathology Department 1, Erasmus University). The mean heart weight was $583 \pm 78 \mathrm{~g}$ (range: $538-700 \mathrm{~g}$ ). The average thickness of the left ventricular wall was $19.5 \pm 1.9 \mathrm{~mm}$.

\section{Case 1}

This specimen was obtained from a 67 year-old female who died suddenly. The aortic valve was tricuspid, with extensive nodular calcifications of the valve cusps projecting into the valve sinuses, but without commissural fusion. These findings were compatible with a degenerative etiology.

\section{Case 2}

The second specimen came from a 71 year-old male patient in whom a pre-mortem cardiac catheterization had shown a mean systolic aortic gradient and a valve area of $70 \mathrm{mmHg}$ and $0.6 \mathrm{~cm}^{2}$, respectively. Mild aortic regurgitation, moderate combined mitral valve disease and subocclusive stenoses of the left anterior descending and circumflex arteries were also present. This patient died after having sustained a large anterior myocardial infarction. At pathological examination, the coexisting mitral valve disease and the tight, heavily calcified commissural fusion between non-coronary and right coronary aortic cusps were in accordance with a rheumatic etiology. Although originally tricuspid, the aortic valve had a bicuspid configuration, owing to the tightly fused commissure. Nodular calcifications on the aortic aspects of the cusps were also observed.

\section{Case 3}

Irreversible cardiogenic shock occurred in this 73 year-old male patient, as a consequence of a posterior myocardial infarction. Post-mortem examination revealed a congenitally bicuspid aortic valve. The larger anterior cusp was divided by a central calcified raphe, extending across the floor of the aortic sinus from aorta to the free edge. The valve had moderate nodular calcifications, but no commissural fusion.

\section{Case 4}

The fourth heart was obtained from a 50 year-old female in whom a previous catheterization had demonstrated a mean systolic aortic gradient of $77 \mathrm{mmHg}$ and a calculated valve area of $0.7 \mathrm{~cm}^{2}$. This patient, while awaiting surgical correction, developed fatal acute pulmonary edema. At autopsy, the valve was also congenitally bicuspid, but with an almost symmetric configuration, a moderate bilateral commissural fusion, and diffuse calcifications confined to the leaflets. In the anterior cusp, a calcified central raphe was also observed.

Specimens were originally preserved in a $10 \%$ formalin solution but were kept in water for 30 days before the experiment. Cylindrical calipers of increasing diameter (range: $3-30 \mathrm{~mm}$ ) were used to assess the aortic orifice area, while the aortic annulus diameter was measured directly. All specimens were examined on a Tomoscan 350 clinical unit (Philips, Philips Medical Systems, Best, Netherlands). Three radiopaque markers were sutured to the aortic wall at the leaflet level and used as reference points in the scanning procedures. Axial scan series, covering the entire aortic valve region, were performed with contiguous scans of $1.5 \mathrm{~mm}$ thickness. Off-line evaluation was performed on a Philips Stand Alone Viewing System, enabling sagittal reconstruction, contour detection of the region of interest, and calculation of volumes and mean computed tomographic attenuation values (Hounsfield 


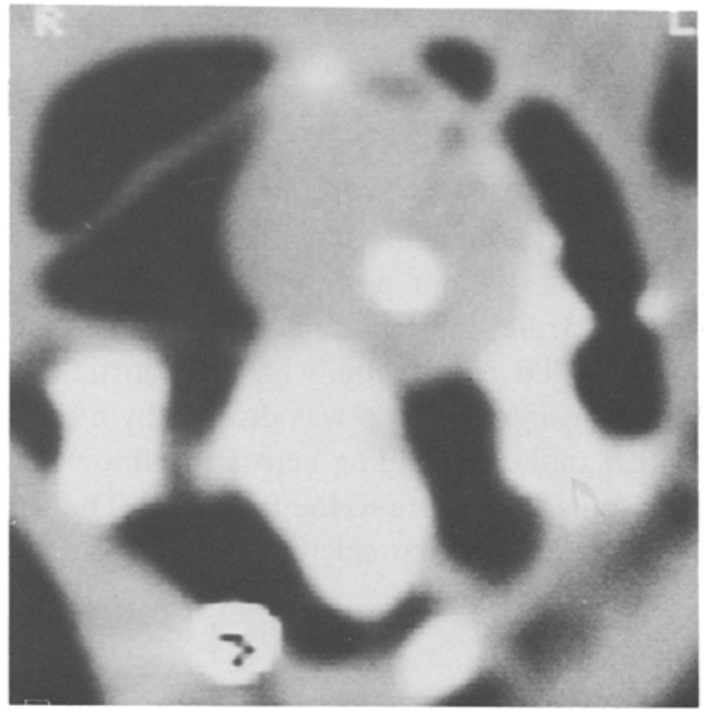

A

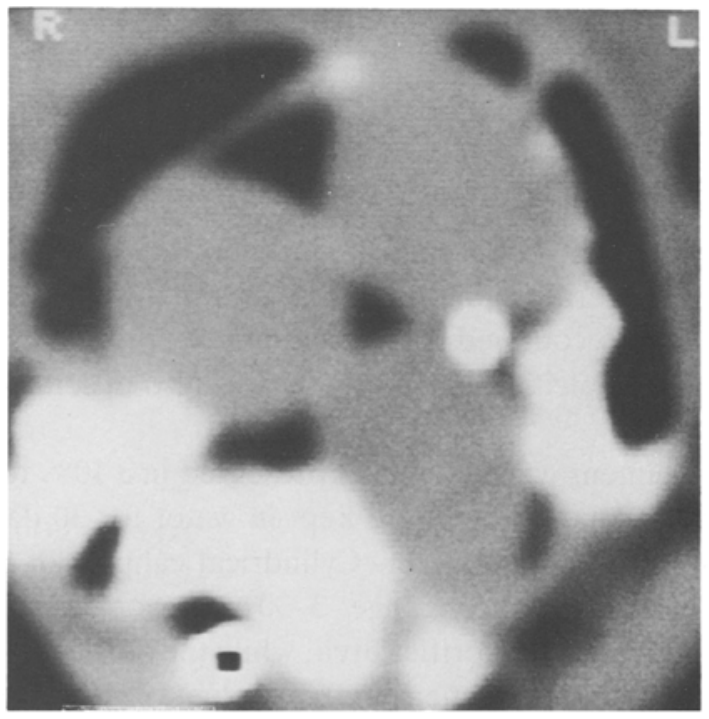

C

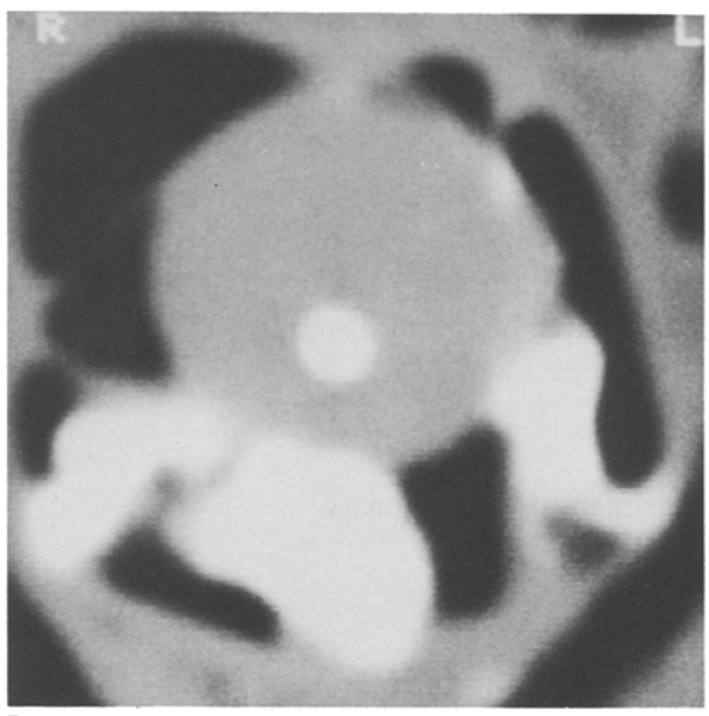

B

Fig. 1. Axial scans of a post-mortem specimen (case \#1) performed at the level of the aortic valve orifice, during inflation of $15 \mathrm{~mm}, 19 \mathrm{~mm}$ and trefoil $3 \times 12 \mathrm{~mm}$ balloons (enlargement factor: $4 \times$ ). This valve was the most heavily calcified. The density is decreasing from white areas (calcium deposits, catheters, radiopaque markers), to the grey (heart and valve soft tissue, water in inflated balloons), and the black areas (air). During inflation, the $15 \mathrm{~mm}$ balloon was displaced towards the less calcified left aortic cusp (Fig. 1A). Minimal increment in valve area was achieved. The inflated $19 \mathrm{~mm}$ balloon occupied also an asymmetrical position in the aortic orifice, but the displacement of the free edges of the cusps was greater than with the previous dilatation, involving also the most heavily calcified leaflet (Fig. 1B). Fracture of nodular calcifications was noted at visual inspection. During inflation of the trefoil balloon (Fig. $1 \mathrm{C})$, a rotating movement was observed. At the end of inflation, the three intercommissural spaces were occupied by the 3 individual components of the balloon, almost totally occluding the aortic orifice. At visual inspection, the increase in cusps mobility was associated with full-thickness fracture of the heavy nodular calcifications. L: left; $R$ : right.

Table 1. Clinical data, macroscopic aspects and computed tomographic evaluation of valve calcium deposits of the four post-mortem specimens

\begin{tabular}{|c|c|c|c|c|c|c|c|}
\hline \multirow[t]{2}{*}{ Case } & \multirow[t]{2}{*}{ Sex } & \multirow[t]{2}{*}{ Age } & \multirow[t]{2}{*}{ No cusps } & \multirow{2}{*}{$\begin{array}{l}\text { Commissural } \\
\text { fusion }\end{array}$} & \multirow{2}{*}{$\begin{array}{l}\text { Valve ring } \\
\text { diameter } \\
(\mathrm{mm})\end{array}$} & \multicolumn{2}{|c|}{ Calcium deposits } \\
\hline & & & & & & Volume $\left(\mathrm{cm}^{3}\right)$ & CT value (HU) \\
\hline 1 & $\mathbf{F}$ & 67 & 3 & No & 24 & 1.21 & 948 \\
\hline 2 & M & 71 & 3 & Yes & 24 & 0.29 & 132 \\
\hline 3 & $\mathbf{M}$ & 73 & 2 & No & 22 & 0.19 & 281 \\
\hline 4 & $\mathrm{~F}$ & 50 & 2 & Yes & 20 & 0.17 & 121 \\
\hline
\end{tabular}

$\mathrm{CT}$ value $=$ computed tomographic attenuation value; $\mathrm{HU}=$ Houndsfield Units; $F=$ female; $M=$ male. 
Units) of calcium deposits. In all specimens the region of interest contour mode was used to determine the residual orifice area during each inflation. Evaluation of all the axial scans was used to assess the minimal free space between leaflets and balloon.

Post-mortem aortic valvuloplasty was performed with balloons of increasing diameter, passed retrogradely from the aorta into the left ventricle. First, a monofoil $15 \mathrm{~mm}$ balloon (inflated cross-sectional area: $1.8 \mathrm{~cm}^{2}$ ) was manually inflated across the aortic valve with a pressure of 3 atmospheres. Thereafter, a second and third dilatation were performed with a monofoil $19 \mathrm{~mm}$ (area: $2.8 \mathrm{~cm}^{2}$ ) and a trefoil $3 \times 12 \mathrm{~mm}\left(3.4 \mathrm{~cm}^{2}\right)$ balloon catheter, ${ }^{*}$ both inflated to a pressure of 3 or 4 atmospheres. Balloons were inflated until complete disappearance of indentation of the valves on the balloons. Leaflet avulsion, valve ring disruption or liberation of valvular debris did not occur in any specimen. Experimental valvuloplasty with bifoil-designed balloon catheters was not assessed in this study, since they were not commercially available at that time in our institution.

Measurement of the aortic valve orifice by cylindrical calipers was performed at the beginning and after each dilatation. Visual inspection, photographs and axial computed tomographic scans were obtained before, during and after each balloon inflation. Figure 1 provides an example of computed axial tomography scans obtained at the level of the aortic valve orifice during experimental valvuloplasty in a post-mortem specimen.

Table 2. Aortic valve area $\left(\mathrm{cm}^{2}\right)$ before experimental valvuloplasty and after dilatation with $15 \mathrm{~mm}, 19 \mathrm{~mm}$ and $3 \times 12 \mathrm{~mm}$ balloons, as calculated by cylindrical calipers

\begin{tabular}{lcccc}
\hline Balloon size & Case 1 & Case 2 & Case 3 & Case 4 \\
\hline BASAL & 0.20 & 0.78 & 0.95 & 0.95 \\
$15 \mathrm{~mm}$ & 0.28 & 1.76 & 0.95 & 0.95 \\
$19 \mathrm{~mm}$ & 0.50 & 2.26 & 1.76 & 1.76 \\
$3 \times 12 \mathrm{~mm}$ & 0.95 & 3.14 & 2.83 & 2.54 \\
\hline
\end{tabular}

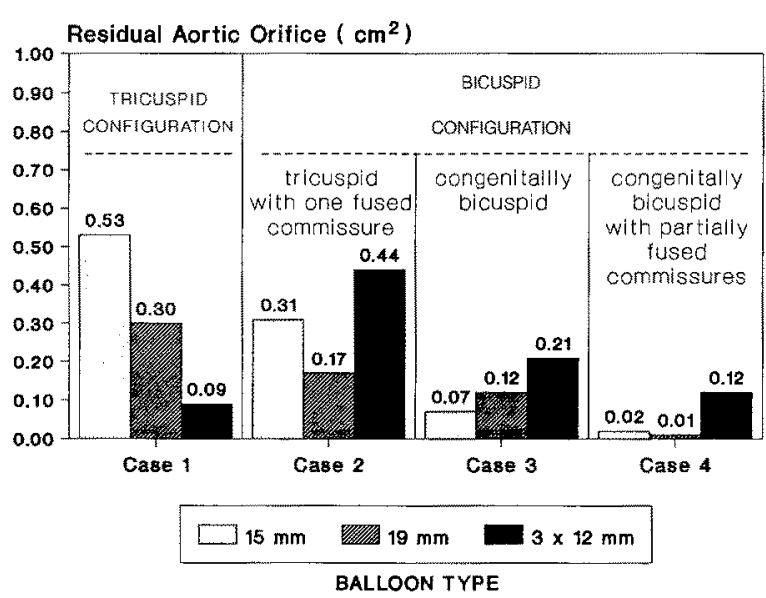

Fig. 2. Computed tomographic evaluation of the residual aortic orifice $\left(\mathrm{cm}^{2}\right)$ during inflation of $15 \mathrm{~mm}, 19 \mathrm{~mm}$ and $3 \times 12 \mathrm{~mm}$ balloons in the post-mortem specimens, as determined by the region of interest contour mode. In cases where a bicuspid configuration was present (cases 2,3 and 4), the trefoil $3 \times$ $12 \mathrm{~mm}$ balloon allowed more free space between balloon and leaflets, while the monofoil $15 \mathrm{~mm}$ and $19 \mathrm{~mm}$ balloons were both more occlusive, despite their smaller cross-sectional surfaces. Conversely, when the valve had a tricuspid configuration (case 1: tricuspid valve without fused commissures), the trefoil balloon was much more occlusive (residual aortic orifice: $0,09 \mathrm{~cm}^{2}$ ) than monofoil $15 \mathrm{~mm}$ and $19 \mathrm{~mm}$ balloons (residual aortic orifice: 0,53 and $0,30 \mathrm{~cm}^{2}$, respectively).

\section{Results and comments}

Table 1 summarizes clinical data and macroscopic aspects of the four valves. Volumes and mean computed tomographic attenuation values of the calcific deposits are also tabulated. Table 2 shows the aortic valve area (AVA) obtained before and after dilatation with $15 \mathrm{~mm}, 19 \mathrm{~mm}$ and $3 \times 12 \mathrm{~mm}$ balloons in each case, as calculated by cylindrical calipers. Figure 2 represents the minimal free space (residual aortic orifice) observed during inflation, as determined by the region of interest contour mode.

During inflation of the $15 \mathrm{~mm}$ balloon, a residual free space between the balloon and the aortic cusps of at least $0.30 \mathrm{~cm}^{2}$ was observed in cases 1 and 2 . However, in presence of a congenitally bicuspid valve (cases 3 and 4), balloon inflation resulted in an almost complete obstruction of the aortic orifice

\footnotetext{
* Schneider Shiley A.G. Zurich, Switzerland.
} 
PATIENT B
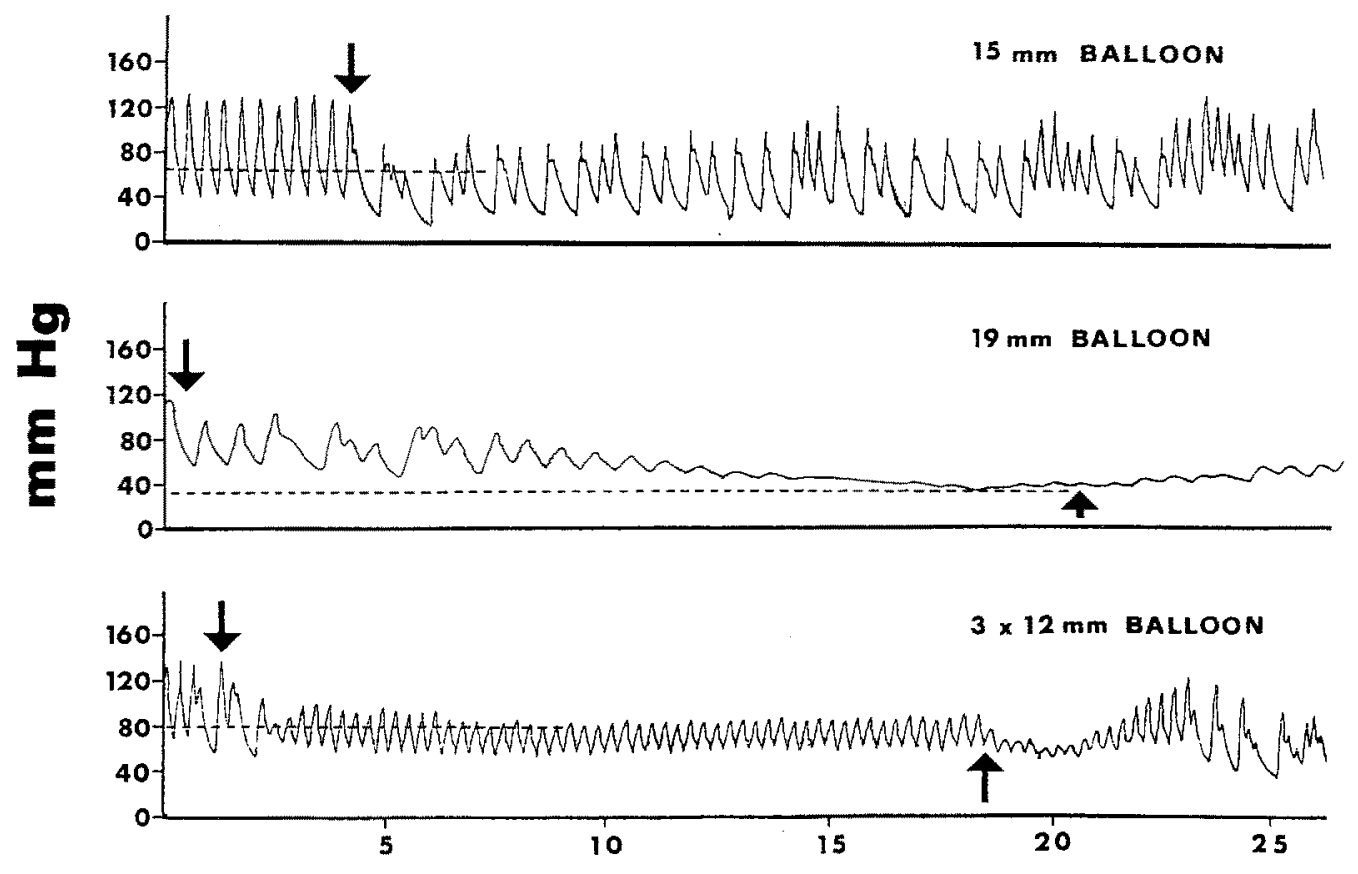

\section{Seconds}

Fig. 3. Patient B: Aortic pressure curves recorded at the time of percutaneous aortic valvuloplasty during dilatation with $15 \mathrm{~mm}$, $19 \mathrm{~mm}$ and $3 \times 12 \mathrm{~mm}$ balloon catheters. In this patient, anatomopathological evaluation tevealed a congenitally bicuspid calcified aortic valve. Balloon inflation is represented by downward arrows $(\downarrow)$ and deflation by upward arrows $(\uparrow)$. The dotted lines show the point on the curves where the lowest systolic aortic pressure values were selected. During dilatation with the $15 \mathrm{~mm}$ balloon (upper tracing), blood pressure dropped rapidly to $60 \mathrm{mmHg}$, but an increase to $80 \mathrm{mmHg}$ was noted shortly after. However, the inflated monofoil $19 \mathrm{~mm}$ balloon (center tracing) was very occlusive, resulting in a marked fall in blood pressure ( $30 \mathrm{mmHg}$ ) and disappearance of the systolo-diastolic waves. The balloon was rapidly deflated after 20 seconds and blood pressure returned almost immediately to $120 \mathrm{mmHg}$ (not shown). No loss of consciousness occurred. During inflation of the $3 \times 12 \mathrm{~mm}$ balloon (lower tracing), the lowest systolic pressure was $80 \mathrm{mmHg}$ and was well tolerated, even if that balloon had the largest inflated cross-sectional area. A transient decrease in blood pressure occurred at the time of deflation. This phenomenon is relatively common during deflation, although not completely understood.

$\left(0.07\right.$ and $0.02 \mathrm{~cm}^{2}$, respectively). No gross fracture of nodular calcifications nor commissural or raphe splitting were observed in any specimen. A moderate increase in AVA occurred only in case 2, while minimal or no changes were achieved in the remaining cases (Table 2). It should be noted that in none of the specimens did the inflated $15 \mathrm{~mm}$ balloon occupy a central position in the aortic orifice. The stretching induced by the balloon was more important on the less calcified, more flexible valve leaflets.
Concerning the $19 \mathrm{~mm}$ balloon, a significant increment in AVA was achieved in all the specimens. Although the balloon still occupied an asymmetrical position in the aortic orifice, larger displacement of the free edges of the cusps were observed, involving the most heavily calcified leaflets. Except in case 1 , which was a tricuspid valve without commissural fusion, this balloon was almost occlusive in the remaining cases. The better residual free space observed in case $1\left(0.30 \mathrm{~cm}^{2}\right)$ can be explained by a wider opening of the leaflets, which in 
turn created an increment in intercommissural spaces. Fracture of nodular calcifications were noted in cases 1 and 2 at visual inspection. Partial commissural separation or central raphe splitting occurred in cases 2, 3 and 4 .

Conversely, despite the larger transverse diameter and cross-sectional area of the inflated $3 \times$ $12 \mathrm{~mm}$ trefoil-shaped balloon, the residual orifice during inflation was paradoxically greater than with previous dilatations in all cases except in case 1 , due presumably to the peripheral and central spaces generated by the trefoil configuration. This advantage of the trefoil shape was already known, but we remarked that it was mostly evident when a 'bicuspid' configuration could be observed (case 2: tricuspid valve with one fused commissure; cases 3 and 4: congenitally bicuspid valves). However, in presence of a tricuspid morphology (case 1), the opposite effect was observed. This may be explained by the rigidity of the leaflets related to the degenerative process, which have oriented passively the individual parts of the inflating trefoil balloon to engage each of the three intercommissural spaces.

Table 3. Clinical data, pathological findings related to the excised valves and hemodynamic data obtained before and after PTAV, in patients who underwent valve replacement after PTAV

\begin{tabular}{|c|c|c|c|c|c|c|}
\hline & & & Patient A & Patient B & Patient C & Patient D \\
\hline $\begin{array}{l}\mathrm{C} \\
\mathrm{L} \\
\mathrm{I}\end{array}$ & Age (years) & & 65 & 73 & 64 & 74 \\
\hline $\begin{array}{l}\mathrm{N} \\
\mathrm{I} \\
\mathrm{C}\end{array}$ & Interval ${ }^{*}$ (months) & & 1 & 10 & 9 & 8 \\
\hline $\begin{array}{l}\text { A } \\
\text { L }\end{array}$ & Reason for surgery & & F & F & $\mathrm{R}$ & $\mathrm{R}$ \\
\hline $\begin{array}{l}\mathrm{P} \\
\mathrm{A} \\
\mathrm{T}\end{array}$ & Valve anatomy & & $\mathrm{T}$ & B & B & $\mathrm{T}$ \\
\hline $\begin{array}{l}\mathrm{H} \\
\mathrm{O} \\
\mathrm{L}\end{array}$ & Commissural fusion & & - & - & - & $+^{* *}$ \\
\hline $\begin{array}{l}\mathrm{O} \\
\mathrm{G}\end{array}$ & Calcifications & & $3+$ & $3+$ & $2+$ & $3+$ \\
\hline Y & Tearing of leaflets & & - & - & - & - \\
\hline $\begin{array}{l}\text { V } \\
\text { A }\end{array}$ & & & & & & \\
\hline $\begin{array}{l}\mathrm{L} \\
\mathrm{V}\end{array}$ & Gradient (mean) & PRE & 50 & 80 & 68 & 74 \\
\hline $\begin{array}{l}U \\
\mathrm{~L} \\
\mathrm{O}\end{array}$ & & POST & 40 & 58 & 41 & 47 \\
\hline $\begin{array}{l}\mathrm{P} \\
\mathrm{L}\end{array}$ & A.V.A. $\left(\mathrm{cm}^{2}\right)$ & Pre & 0.5 & 0.3 & 0.4 & 0.5 \\
\hline $\begin{array}{l}\text { A } \\
\text { S } \\
\text { T } \\
\text { Y }\end{array}$ & & POST & 0.6 & 0.4 & 0.7 & 0.7 \\
\hline
\end{tabular}




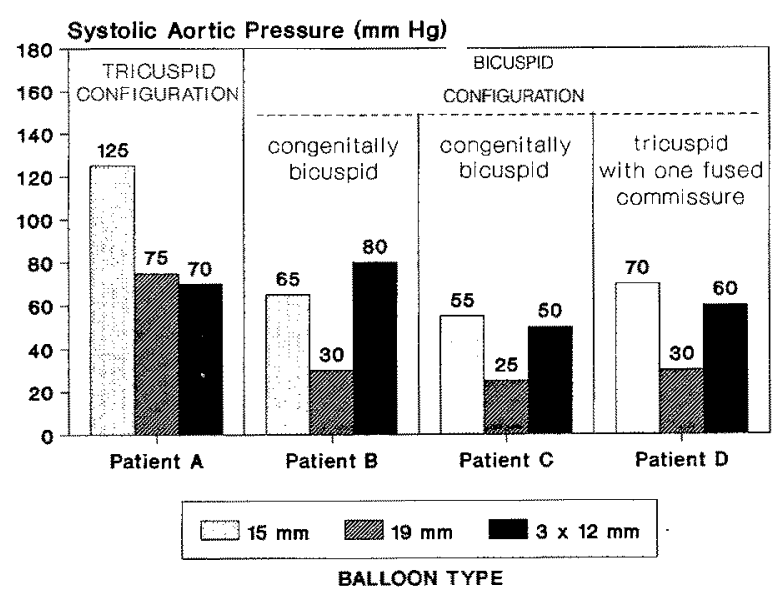

Fig. 4. Lowest systolic aortic pressure values recorded during inflation of monofoil $15 \mathrm{~mm}, 19 \mathrm{~mm}$ and trefoil $3 \times 12 \mathrm{~mm}$ balloons in four patients who underwent elective percutaneous aortic valvuloplasty 1 to 10 months before valve replacement. In cases where more than one inflation was performed with the same balloon catheter, the curve showing the lowest systolic pressure value was selected. In patients in whom a bicuspid configuration was present $(B$ and $C$. congenitally bicuspid valves; $D$ : tricuspid valve with one commissural fusion not separated by balloon valvuloplasty), the $19 \mathrm{~mm}$ balloon generated a more dramatic fall in blood pressure and was less tolerated than the larger trefoil $3 \times 12 \mathrm{~mm}$ balloon $(30 \mathrm{vs} 80 \mathrm{mmHg}, 25 \mathrm{vs}$ $50 \mathrm{mmHg}$, and $30 \mathrm{vs} 60 \mathrm{mmHg}$, respectively). Conversely, in patient A (tricuspid valve without commissural fusion), the trefoil balloon offered no advantage compared to the $19 \mathrm{~mm}$ balloon, as reflected by the slightly lower blood pressure observed during the $3 \times 12 \mathrm{~mm}$ balloon inflation.

\section{Clinicopathological observations}

In order to compare the results of experimental valvuloplasty to the clinical situation, we analysed retrospectively aortic pressure curves recorded during dilatation at the time of PTAV in patients who underwent subsequently a valve replacement. We have correlated these hemodynamic data with the anatomopathological evaluation of the surgically excised aortic valves.

\section{Methods}

From March 1986 to October 1988, thirty-five elderly patients underwent PTAV in our institution. The technique of the valvuloplasty procedure itself in our institution has been described earlier by our group [10]. Ten of these patients subsequently underwent an aortic valve replacement ( 6 for restenosis, 3 for a failed procedure and one patient for severe aortic regurgitation). In four of these surgical patients, a stepwise dilatation with $15 \mathrm{~mm}$, $19 \mathrm{~mm}$ and trefoil $3 \times 12 \mathrm{~mm}$ balloons had been performed, in the same sequence as during our in vitro experiments described above. Two of these patients underwent surgery for failed PTAV, since increments in AVA achieved by valvuloplasty were only minimal, without significant symptomatic improvement. The two other patients underwent valve replacement for recurrence of stenosis, defined as a clinical recurrence of symptoms with either a return of maximal aortic valve flow velocity to pre-valvuloplasty values on echo-Doppler flow measurements, or an invasively measured AVA which was less than $25 \%$ larger than before PTAV.

The hemodynamic repercussion of aortic orifice obstruction generated by balloon inflation was assessed by the systolic aortic pressure, continuously recorded throughout the procedure by a $7 \mathrm{~F}$ pigtail catheter positioned in the descending aorta. Systolic aortic pressure values were obtained by reviewing the aortic pressure tracings recorded on paper during the PTAV procedures. The pressure curves recorded during dilatation were analyzed and the lowest systolic aortic pressure values (nadir) were selected. Since the pressure scale on the recording paper grid was $4 \mathrm{mmHg} / \mathrm{mm}$, the lowest systolic aortic pressure value was arbitrarily rounded to $5 \mathrm{mmHg}$ (for example: $12 \mathrm{~mm}=48 \mathrm{mmHg}$; rounded to $50 \mathrm{mmHg}$ ). In cases where more than one inflation was performed with the same balloon, the pressure curve showing the lowest systolic aortic pressure value was selected. Figure 3 gives an example of the aortic pressure curves recorded during a valvuloplasty procedure.

\section{Results and comments}

Table 3 summarizes clinical data, pathological findings related to the excised valves and hemodynamic data of the PTAV procedures. Figure 4 illustrates the lowest systolic aortic pressure recorded in the 
four patients, when the different balloons were fully inflated.

The mean age was 69.0 years (range: 64-75 years) and the mean time interval between PTAV and valve replacement was 7.0 months (range: $1-10$ months). Despite the limited number of patients available, we noted that in patients in whom a bicuspid valve configuration was present (patients $B$ an $C$ : congenitally bicuspid valves; patient $D$ : tricuspid valve with one fused commissure in which PTAV did not result in commissural separation), dilatation with the single circular $19 \mathrm{~mm}$ balloon was less well tolerated than with the larger $3 \times$ $12 \mathrm{~mm}$ trefoil balloon, as revealed by the systolic aortic pressure during inflation (Fig. 4). These observations correlated well with our experimental findings, which have shown that inflated trefoilshaped $3 \times 12 \mathrm{~mm}$ balloons allowed more residual free space in presence of a bicuspid configuration.

Conversely, pathological examination of the aortic valve in patient $A$ revealed a calcified tricuspid valve without commissural fusion (i.e. tricuspid configuration), in accordance with a degenerative etiology. In this case, dilatation with the $3 \times 12 \mathrm{~mm}$ balloon did not appear to offer any advantage, being as occlusive as the $19 \mathrm{~mm}$ circular balloon (Fig. 4). These findings do not confirm but suggest strongly that intercommissural spaces may have been obstructed by each of the three individual parts of the trefoil balloon, as observed in our in vitro experiments.

\section{Discussion}

In contrast with other valvular heart diseases in which balloon valvuloplasty has been applied, acquired AS in the elderly is characterized by a broad spectrum of valvular morphology. We have assessed qualitatively and quantitatively the effects of dilatation with different balloons in aortic valves of various morphology (bicuspid, tricuspid, fused and non-fused commissures) and etiology (degenerative, congenital and rheumatic), but the extrapolation of our experimental results to other cases with different anatomy should be made with caution.
The increments in AVA achieved after experimental valvuloplasty were much greater than those reported in clinical trials. It seems unlikely that this discrepancy was related to the effects of formalin fixation. In fact, formalin preservation alters valvular fibrous proteins and leads to stiffening of the valve leaflets and reduction of the elastic properties of the aortic cusps, resulting in increased rigidity of the aortic valve leaflets. Thus, it seems conceivable that smaller increments in AVA would have been obtained after formalin fixation. However, it should be noted that previous reports [26] compared the effects of balloon dilatation on 27 calcific, stenotic aortic valves dilated after variable periods of fixation in formalin and on 12 non-preserved valves dilated either at post-mortem examination or in the operating room and observed no apparent difference in results. In our experimental study, the greater increments in AVA, compared to those achieved in the clinical situation, are rather explained by: 1) easy and optimal positioning of the balloon in a non-beating heart, 2) the possibility to perform prolonged inflation time without creating adverse effects such as hypotension and 3) direct measurement of AVA by cylindrical calipers, which differs greatly from the Gorlin's formula used in live patients.

Our experimental observations have demonstrated that use of balloons with diameter smaller than $19 \mathrm{~mm}$ resulted generally in minimal or no increment in aortic valve area. The radial forces of the inflating $15 \mathrm{~mm}$ balloon were initially applied on the less calcified and more flexible leaflets and the space occupied by the fully inflated balloon was not sufficient to displace substantially the free edges of the more rigid leaflets. This was depicted by the asymmetrical position of the inflated $15 \mathrm{~mm}$ balloon observed in all the experimental cases. Clinical experience has also shown that better hemodynamic improvements can usually be achieved with balloons of larger diameter [30]. Some authors advocate the use of oversized balloons (i.e. larger than the aortic ring) to obtain better hemodynamic results [31] but some controversies still exist, based mainly on the fear of producing catastrophic complications such as tearing of aortic leaflets or aortic wall dissection, resulting in major aortic regurgita- 
tion, cardiac tamponnade or fatal aortic rupture $[32,33]$. Furthermore, acquired aortic stenosis is frequently associated with extensive calcific vegetations, protruding into the valve sinuses. During balloon inflation, this calcium bulk may prevent the complete apposition of the aortic leaflets against the aortic wall. If oversized balloons are used in this situation, the trapped calcific vegetations can further increase the mechanical stress generated by the inflating balloon on the aortic wall, which may lead to disastrous consequences. Extensive calcifications may also provide additional explanations on the limited hemodynamic improvements achieved by PTAV in a non negligeable proportion of patients [19]. For instance, the lowest obtained AVA in our experimental study occurred in the most heavily calcified valve (case 1), reflected by the largest volume and the highest density on computed tomographic scanning (Table 1). In our clinical observations, the failed PTAV procedures occurred in patients $A$ and $B$, in whom aortic valves were also heavily calcified.

Trefoil balloons have been developed in attempt to avoid complete interruption of blood flow during inflation and to reduce the frequency of marked hypotension during valvuloplasty procedures. This advantage has been observed during inflation across the aortic valve in dogs, in pulmonary valvuloplasty in adults, aortic valvuloplasty in children and young adults, and in mitral and aortic valvuloplasty in adults [20-24]. Our experimental and clinical observations suggest that trefoil balloons allow a larger residual orifice and can provide a better blood flow during inflation in presence of a bicuspid configuration, despite its superior inflated cross-sectional area $\left(3.4 \mathrm{~cm}^{2}\right)$ compared to the circular $19 \mathrm{~mm}$ balloon (area: $2.8 \mathrm{~cm}^{2}$ ); on the contrary, the trefoil-shaped balloon does not appear to offer the same advantages in presence of a tricuspid aortic configuration. In order to compare the trefoil $3 \times 12 \mathrm{~mm}$ balloon with a single circular balloon of equivalent diameter, experimental valvuloplasty using a monofoil $25 \mathrm{~mm}$ balloon would have been interesting, but this size was not commercially available at the time of our in vitro experiments. Nevertheless, it seems conceivable that the obtained results would have been similar in cases where a bicuspid configuration was present, since the $19 \mathrm{~mm}$ balloon was already almost completely occlusive.

Balloon catheters with a bifoil design have also been introduced recently. As mentioned previously, bifoil balloons were not assessed in our study, since they were not commercially available in our institution at the time of our in vitro experiments and they have not been used during valvuloplasty procedures in patients from whom our clinicopathological observations were derived. In a recent report of Voudris et al. [34], it has been stated that bifoil balloons offered better hemodynamic results and a better tolerance during inflation than monofoil and trefoil balloon catheters. The balloon catheters assessed in that study were monofoil $19 \mathrm{~mm}$ (inflated area: $2.8 \mathrm{~cm}^{2}$ ), bifoil $2 \times 15 \mathrm{~mm}$ (area: $3.5 \mathrm{~cm}^{2}$ ) and trefoil $3 \times 10 \mathrm{~mm}$ (area: $2.4 \mathrm{~cm}^{2}$ ). The better hemodynamic results achieved may be related simply to the greater inflated area of the bifoil balloon used in that study. They also reported a higher rate of marked hypotension in the group of patients in which a $3 \times 10 \mathrm{~mm}$ trefoil balloon was used. However, this subgroup had the more depressed left ventricular function before PTAV; thus, the relatively poorer tolerance of inflation observed might not be entirely related to the trefoil design. Furthermore, since the valvular configuration was not known, it may be speculated that some of these patients had indeed aortic valves with tricuspid configuration and according to our observations, use of trefoil balloons in this situation can lead to an almost complete interruption of aortic flow and severe hypotension. Further experimental studies with monofoil, bifoil and trefoil balloon catheters of equivalent inflated cross-sectional areas, assessed in different valvular configurations, would certainly be very useful for improving our knowledge of the balloon - leaflets relationship in PTAV.

\section{Conclusion}

Our experimental and clinicopathological observations have shown that the degree of aortic orifice obstruction during inflation of a monofoil or a tre- 
foil balloon is dependent on the underlying valvular morphology. In our opinion, these observations are relevant, since degenerative disease of the aortic valve is now recognized as the most common etiology of aortic stenosis in the elderly, based on the knowledge of the changing natural history of aortic stenosis observed since a few decades [35]. Some authors have also reported that heavily calcified congenitally bicuspid aortic valves were at higher risk for complications from PTAV, such as irreversible hypotension [36]. These findings demand that, in clinical practice, a careful assessment of the valvular anatomy should be attempted in patients in whom PTAV is planned, in order to individualize the choice of the valvuloplasty material and to optimize the tolerance of the procedure. Unfortunately, accurate characterization of the valvular morphology of stenotic aortic valves in elderly patients can be often misleading, due to remodeling of the valve architecture by the degenerative process and calcium deposition. Until now, conventional techniques such as contrast angiography and precordial echocardiography have not been proved to be reliable for assessing accurately the valvular morphology of acquired AS. Transesophageal [37] or intravascular echography [38] can be valuable techniques to provide useful images of valvular anatomy and represent promising solutions to this diagnostic problem, especially in obese or emphysematous patients. Fiberoptic angioscopy can also provide diagnostic informations on aortic valvular morphology [36], but probably with a lesser degree of accuracy and applicability, compared to transesophageal and intravascular ultrasound imaging.

However, all these techniques have the major disadvantage to be relatively invasive. But recently, ultrafast computed tomography has been used in the diagnosis of aortic valve stenosis and assessment of its severity in a small number of patients $[39,40]$. Good correlations with catheterizationderived AVA have been obtained and in some patients, heavily calcified bicuspid and tricuspid aortic valves were clearly identified. Even if the overall accuracy is not yet defined, this noninvasive technique seems very promising as a diagnostic adjunct to improve the safety of PTAV.

\section{References}

1. Cribier A, Saoudi N, Berland J, Savin T, Rocha P, Letac B. Percutaneous transluminal valvuloplasty of acquired aortic stenosis in elderly patients: an alternative to valve replacement? Lancet 1986; 1: 63-7.

2. Serruys PW, de Feyter PJ, van den Brand M. Percutaneous transluminal valvuloplasty of stenotic aortic valve in an elderly patient (dutch publication). Hart Bull 1986; 17: $171-75$.

3. Cribier A, Savin T, Berland J, Rocha P, Mechmeche R, Saoudi N, Behar P, Letac B. Percutaneous transluminal balloon valvuloplasty of adult aortic stenosis: report of 92 cases. J Am Coll Cardiol 1987; 9: 381-86.

4. Di Mario C, Beatt KJ, van den Brand M, de Feyter PJ, Essed CE, Serruys PW. Percutaneous balloon dilatation in elderly patients with calcific aortic stenosis. Immediate hemodynamic assessment and short-term clinical follow-up. Br Heart J 1987; 58: 644-52.

5. Isner JM, Salem BN, Desnoyers MR, Hougen TJ, Mackey WC, Pandian NG, Eichhorn EJ, Konstam MA, Levine HJ. Treatment of calcific aortic stenosis by balloon valvuloplasty. Am J Cardiol 1987; 59: 313-17.

6. McKay RG, Safian RD, Lack JE, Diver DJ, Berman AD, Warren SE, Come PC, Baims DS, Mandell VE, Royal HD, Grossman W. Assessment of left ventricular and aortic valve function after aortic balloon valvuloplasty in adult patients with critical aortic stenosis. Circulation 1987; 75: 192-203.

7. Drobinski G, Lechat P, Metzger JP, Lepailleur C, Vacheron A, Grosgogeat Y. Results of percutaneous catheter valvuloplasty for calcified aortic stenosis in the elderly. Eur Heart J 1987; 8: 322-28.

8. Commeau P, Grollier G, Lamy E, Foucault JP, Durand C, Maffei G, Maiza D, Khayat A, Potier JC. Percutaneous balloon dilatation of calcific aortic valve stenosis: anatomical and hemodynamic evaluation. Br Heart J 1988; 59: 227-38.

9. Serruys PW, Di Mario C, Essed CE. Restenosis 3 months after successful percutaneous aortic valvuloplasty. A clinicopathological report. Int J Cardiol 1987; 17: 210-13.

10. Serruys PW, Luijten HE, Beatt KJ, Di Mario C, de Feyter PJ, Essed CE, Roelandt JRTC, van den Brand M. Percutaneous balloon valvuloplasty for calcific aortic stenosis. A treatment 'sine cure'? Eur Heart J 1988; 9: 782-94.

11. Meany BT, Sprigings D, Chambers J, Monaghan M, Thomas $\mathrm{S}$, Jackson G, Jewitt DE. Aortic valvuloplasty in the elderly: is restenosis inevitable? (abstract). Circulation 1988; 78 (Suppl. II): 531.

12. Berland J, Cribier A, Letac B, Guermonprey JL. Percuta neous aortic valvuloplasty in adults: immediate results of the French Registry (abstract). Eur Heart J 1987; 8 (Suppl. 2): 241 .

13. Litvack F, Jakubowski AT, Buchbinder NA, Eigler N. Lack of sustained clinical improvement in an elderly pop- 
ulation after percutaneous aortic valvuloplasty. Am J Cardiol 1988; 62: 270-75.

14. Desnoyers MR, Isner JM, Pandian NG, Wang SS, Hougen $T$, Fields CD, Lucas AR, Salem DN. Clinical and noninvasive hemodynamic results after aortic balloon valvuloplasty for aortic stenosis. Am J Cardiol 1988; 62: 1078-84.

15. Nishimura RA, Holmes Jr DR, Reeder GS, Orszulak TA, Bresnahan IF, Ilstrup DM, Tajik AJ. Doppler evaluation of results of percutaneous aortic balloon valvuloplasty in calcific aortic stenosis. Circulation 1988; 78: 791-99.

16. Safian RD, Berman AD, Diver DJ, McKay LL, Come PC, Riley MF, Warren SE, Cunningham MJ, Wyman RM, Weinstein IS, Grossman W, McKay RG. Balloon aortic valvuloplasty in 170 consecutive patients. $N$ Engl J Med 1988; 319: 125-30.

17. Levine MJ, Berman AD, Safian RD, Diver DJ, McKay RG. Palliation of valvular aortic stenosis by balloon valvuloplasty as preoperative preparation for noncardiac surgery. Am J Cardiol 1988; 62: 1309-10.

18. Block PC. Aortic valvuloplasty - A valid alternative? N Engl J Med 1988; 319: 169-71.

19. Letac B, Gerber LI, Koning R. Insights on the mechanism of balloon valvuloplasty in aortic stenosis. Am $\mathrm{J}$ Cardiol 1988; 62: 1241-47.

20. Meier B, Friedli B, Oberhaensli I, Belenger J, Finci L. Trefoil balloon for percutaneous valvuloplasty. Cathet Cardiovasc Diagn 1986; 12: 277-81.

21. van der Berg EJM, Niemeyer MG, Plokker TWM, Ernst SMPG, de Korte J. New triple-lumen balloon catheter for percutaneous pulmonary valvuloplasty. Cathet Cardiovasc Diagn 1986; 11: 352-56.

22. Meier B, Friedli B, Oberhaensli I. Trefoil balloon for aortic valvuloplasty. Br Heart J 1986; 56: 292-93.

23. Vahanian A, Michel PL, Slama M, Cormier B, Savier C, Acar J. Percutaneous mitral commissurotomy by a trefoil balloon in adults (abstract). Circulation 1986; 74 (Suppl. 2): 204.

24. Meier B, Friedli B, Segesser L. Valvuloplasty with trefoil and bifoil balloons and the long-sheath technique. Herz 1988; 13: 1-13.

25. McKay RG, Safian RD, Lock JE, Mandell VS, Thurer RE, Schnitt SJ, Grossman W. Balloon dilatation of calcific aortic stenosis in elderly patients: post-mortem, intra-operative, and percutaneous valvuloplasty studies. Circulation 1986; 74: 119-25.

26. Safian RD, Mandell VS, Thurer RE, Hutchins GM, Schnitt SJ, Grossman W, McKay RG. Post-mortem and intraoperative balloon valvuloplasty of calcific aortic stenosis in elderly patients. J Am Coll Cardiol 1987; 9: 655-60.

27. Vahanian $A$, Guerinon J, Michel PL, Slama M, Griveaux M, Acar J. Experimental balloon valvuloplasty of calcified aortic stenosis in the elderly (abstract). Circulation 1986; 74 (Suppl. II): 365 .

28. Di Mario C, van Veen L, de Baat L, Essed CE, Beatt KJ,
Leborgne O, Serruys PW. Computed tomography during experimental balloon dilatation for calcific aortic stenosis. A look into the mechanism of valvuloplasty. J Interven Cardiol 1988; 1: 95-107.

29. Serruys PW, Di Mario C, Beatt KJ, van Veen LCP, de Feyter $P$, Suryapranata $H$, van den Brand M, Essed CE. Valvuloplasty for calcific aortic stenosis. Cardiac Imaging Video Journal $1989 ; 2$, $\mathrm{nr} 4$.

30. Cribier A, Grigera F, Eltchaninoff $H$, Lefebvre E, Berland $\mathrm{J}$, Letac B. New developments in aortic balloon valvuloplasty (abstract). J Am Coll Cardiol 1989; 13: 17A.

31. Rocha P, Baron B, Lacombe P, Bernier A, Kahn JC, Liot $F$, Bourdarias JP. Aortic percutaneous transhuminal valvuloplasty in elderly patients by balloon larger than aortic annulus. Cathet Cardiovasc Diagn 1988; 15: 81-88.

32. Vrolix M, Piessens J, Moerman P, Vanhaecke J, De Geest H. Fatal aortic rupture: an unusual complication of percutaneous balloon valvuloplasty for acquired valvular aortic stenosis. Cathet Cardiovasc Diagn 1989; 16: 119-22.

33. Lewin RF, Dorros G, King JF, Seifert PE, Schmahl TM, Auer JE. Aortic annular tear after valvuloplasty: the role of aortic annulus echocardiographic measurement. Cathet Cardiovasc Diagn 1989; 16: 123-29.

34. Voudris V, Drobinski G, L'Epine Y, Sotirov I, Moussallem $N$, Canny $M$. Results of percutaneous valvuloplasty for calcific aortic stenosis with different balloon catheters. Cathet Cardiovase Diagn 1989; 17:80-83.

35. Selzer $A$. Changing aspects of the natural history of valvular aortic stenosis. N Engl J Med 1987; 317: 91-116.

36. Fields CD, Isner JM. Balloon valvuloplasty in adults. Cardiology Clinics 1988; 6: 383-419.

37. Cyran SE, Kimball TR, Schwartz DC, Meyer RA, Steed RD, Kaplan S. Evaluation of balloon aortic valvuloplasty with transesophageal echocardiography. Am Heart J 1988; 115: 460-62.

38. Pandian NG, Kreis A, Brockway B, Isner JM, Sacharoff A, Boleza E, Caro R, Muller D. Ultrasound angioscopy: realtime, two-dimensional, intraluminal ultrasound imaging of blood vessels. Am J Cardiol 1988; 62: 493-94.

39. MacMillan RM, Rees MR, Lumia MJ, Maranhao V. Preliminary experience in the use of ultrafast computed tomography to diagnose aortic valve stenosis. Am Heart J 1988; 115: $665-71$.

40. Fields CD, Isner JM. Ultrafast CT in aortic stenosis (letter). Am Heart J 1988; 116: 1647.

Address for offprints:

P.W. Serruys,

Catheterization Laboratory,

Thoraxcenter, Erasmus University, P.O. Box 1738, 3000 DR Rotterdam,

The Netherlands 